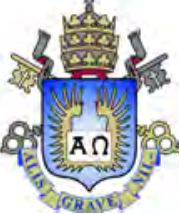

Guilherme Coelho Netto Avelar

Drug Markets and Violence: Evidence from

Brazil

Dissertação de Mestrado

Thesis presented to the Programa de Pós-graduação em Economia da PUC-Rio in partial fulfillment of the requirements for the degree of Mestre em Economia.

Advisor: Prof. Claudio Abramovay Ferraz do Amaral 
Guilherme Coelho Netto Avelar

\section{Drug Markets and Violence: Evidence from}

Brazil

Thesis presented to the Programa de Pós-graduação em Economia da PUC-Rio in partial fulfillment of the requirements for the degree of Mestre em Economia. Approved by the undersigned Examination Committee.

Prof. Claudio Abramovay Ferraz do Amaral

Advisor

Departamento de Economia - PUC-Rio

Prof. Joana Monteiro

Departamento de Economia - PUC-Rio

Prof. Gustavo Gonzaga

Faculdade de Economia e Administração - USP

Prof. Monica Herz

Coordinator of the Centro de Ciências Sociais - PUC-Rio 
All rights reserved.

\section{Guilherme Coelho Netto Avelar}

B.A., Economics, IBMEC-Rio, 2014.

Bibliographic data

Avelar, Guilherme Coelho Netto

Drug markets and violence : evidence from Brazil / Guilherme Coelho Netto Avelar; advisor: Claudio Abramovay Ferraz do Amaral. - Rio de janeiro: PUC-Rio, Departamento de Economia, 2017.

v., 39 f: il. color. ; $30 \mathrm{~cm}$

Dissertação (mestrado) - Pontifícia Universidade Católica do Rio de Janeiro, Departamento de Economia.

Inclui bibliografia

1. Economia - Teses. 2. Crime;. 3. Tráfico de Drogas;. 4. Uso de Drogas;. 5. Violência;. 6. Entrada de Drogas;. I. Abramovay Ferraz do Amaral, Claudio. II. Pontifícia Universidade Católica do Rio de Janeiro. Departamento de Economia. III. Título.

CDD: 330 


\section{Acknowledgments}

I would like to thank my parents, Ana and André, for all the support. I thank my advisor, Claudio Ferraz, for the guidance given to me through all this period. I am also thankful for all the support given by my friends. And lastly, but most importantly, Laís. 


\section{Abstract}

Coelho Netto Avelar, Guilherme; Abramovay Ferraz do Amaral, Claudio (Advisor). Drug Markets and Violence: Evidence from Brazil. Rio de Janeiro, 2017. 39p. Dissertação de mestrado - Departamento de Economia, Pontifícia Universidade Católica do Rio de Janeiro.

We use data for hospitalizations due to drug use, and we create a measure for the emergence of drug markets (drug entry) in Brazilian municipalities. Using this measure, we ask whether drug entry is associated with the rise in violence seen in Brazil during the 2000's. We estimate a positive association between drug entry and homicide rates, with a stronger association for homicides against young males murdered by fire weapons. We also find that the presence of slums makes this association stronger.

\section{Keywords}

Crime; Drug Trafficking; Drug Use; Violence; Drug Entry; 


\section{Resumo}

Coelho Netto Avelar, Guilherme; Abramovay Ferraz do Amaral, Claudio. Mercados de Drogas e Violência: Evidências do Brasil. Rio de Janeiro, 2017. 39p. Dissertação de Mestrado Departamento de Economia, Pontifícia Universidade Católica do Rio de Janeiro.

Nós usamos dados de internações por uso de drogas para criar uma medida do crescimento do mercado de drogas (entrada de drogas) para os municípios brasileiros durante os anos 2000. Usando essa medida, nós perguntamo se existe uma associação entre entrada de drogas e o aumento da violência visto nos anos 2000. Nós estimamos uma associação positiva entre entrada de drogas e violência, com uma associação mais forte para homicídios contra homens jovens mortos por armas de fogo. Nós também mostramos que a presença de favelas aumenta essa associação.

\section{Palavras-chave}

Crime; Tráfico de Drogas; Uso de Drogas; Violência; Entrada de Drogas; 


\section{Table of contents}

$\begin{array}{lll}1 & \text { Introduction } & 10\end{array}$

2 Related Literature and Contribution $\quad 12$

3 Is drug entry associated with violence? $\quad 14$

$\begin{array}{lll}3.1 \text { Data } & 14\end{array}$

3.1.1 Description of Drug Entry 15

$\begin{array}{lll}3.2 & \text { Empirical Strategy } & 18\end{array}$

$\begin{array}{lll}3.3 & \text { Results } & 20\end{array}$

3.3.1 Dynamic of the relation between drug entry and violence 22

$\begin{array}{lll}3.4 & \text { Robustness Checks } & 23\end{array}$

4 Heterogeneity $\quad 26$

4.1 Which groups suffer more with the violence rise from drug entry? 26

4.2 Effects of Drug Entry by Slum Presence 29

$\begin{array}{lll}5 & \text { Conclusion } & 31\end{array}$

$\begin{array}{ll}\text { Bibliography } & 33\end{array}$

$\begin{array}{lll}\text { A Appendix } & 37\end{array}$ 


\section{List of figures}

Figure 1.1 Homicide Rates by Region from 1979 to 2014

Figure 3.1 Municipalities where at least 10 hospitalizations due to drug use occurred from 1998 to $2013 \quad 16$

$\begin{array}{lll}\text { Figure 3.2 Drug Entry by Municipality - 2000 } & 17\end{array}$

$\begin{array}{lll}\text { Figure 3.3 Drug Entry by Municipality - } 2012 & 18\end{array}$

Figure 3.4 The dynamic of the relation between drug entry and violence

Figure 4.1 The dynamic of the relation between drug entry and violence by groups

Figure 4.2 The dynamic of the relation between drug entry and violence by groups - Log transformed model 


\section{List of tables}

Table 3.1 Is drug entry associated with violence? 22

Table 3.2 Robustness Checks 24

Table 4.1 Is the association between drug entry and violence stronger for some groups? 28

Table 4.2 Is the association between drug entry and violence stronger for some groups? (Log transformed model) 28

Table 4.3 Is the presence of slums making the association between drug entry and violence stronger? 30

Table A.1 Is drug entry associated with violence? (Cutoffs: 1, 2, 4) 37

Table A.2 Is drug entry associated with violence? (Cutoffs: 8, 12, 16) 37

Table A.3 Is drug entry associated with violence? (Cutoffs: 1, 2, 4)

- Log Transformed OLS

Table A.4 Is drug entry associated with violence? (Cutoffs: 8, 12, 16) - Log Transformed OLS

Table A.5 Is drug entry associated with violence? (Cutoffs: 1, 2, 4) - Poisson Regression

Table A.6 Is drug entry associated with violence? (Cutoffs: 1, 2, 4)

- Poisson Regression 


\section{1 \\ Introduction}

Violence related to illegal markets is widespread throughout the world. In this environment, agents are unable to rely on a central authority to enforce property rights and guarantee previously agreed contracts. Armed groups often act violently in order to secure their assets and obtain new resources $(21,62,63,65,64)$.

In this paper, we study the connection between drug markets and violence in the Brazilian context. In our setting, drug markets are seen as being consumer-based $^{1}$ which is contrary to what is normally considered in other settings where drug markets are associated with cocaine production and trade, in Latin America, and opium, in Asia. In the Brazilian context, consumer-based drug markets were often associated with the cities of Rio de Janeiro and São Paulo, which experienced, and to some extent still experience, a large increase in drug-related violence during the 1990's (61). We follow more recent evidence showing a widespread increase in drug consumption during the 2000's, specially cocaine and its derivatives, in a much broader scope, comprising all regions of the country $(11,24)$.

Figure 1.1 shows the evolution of homicide rates for the 5 regions of Brazil. We observe that, since the beginning of the 2000's, there is a clear upward trend for the Northeast, North and South regions. Moreover, the metropolitan region of São Paulo, situated in the Southeast, and the main contributor to the downward trend in the 2000's, had the same experience during the 1980's and 1990's, a period of increased crack cocaine consumption $(61,60)$. More generally, the Brazilian case is very alarming. For instance, around the year 2010 the country reached the mark of 50,000 homicides. To put in perspective, The United Nations Office on Drugs and Crime ranked it 15 th place among countries with most homicides per capita and first for most homicides overall.

We ask whether the emergence of drug markets (drug entry) during the 2000's was associated with the rise in violence in the period from 1998 to 2013. For this, we use data provided by SUS, Brazil's public funded

\footnotetext{
${ }^{1}$ It's important to note that in Brazil trade is responsible for a big portion of the drug
} market. 
health care system, on hospitalizations due to drug use in order to create a measure of the timing of drug entry in Brazilian municipalities. This measure essentially identifies the drug entry through a sudden large enough spike in hospitalizations.

Our results show that drug entry, as measured by sudden increases in hospitalizations due to drug use, is positively associated with the rise in violence. The estimates are large in magnitude, and we find results with an increase range of $13,5 \%$ to $25 \%$ on homicide rates for the average municipality, depending on the model. We also show that the association between drug entry and violence is stronger for young males murdered by fire weapons. We argue that this is an indicative of deaths occurring inside drug markets, i.e., between the agents participating in these markets, although it's difficult to point out if this is related to drug traffickers fighting each other for territory or due to the lack of payment form drug users, for example. We also show that the presence of slums, where the state is widely absent in Brazil, makes this association stronger.

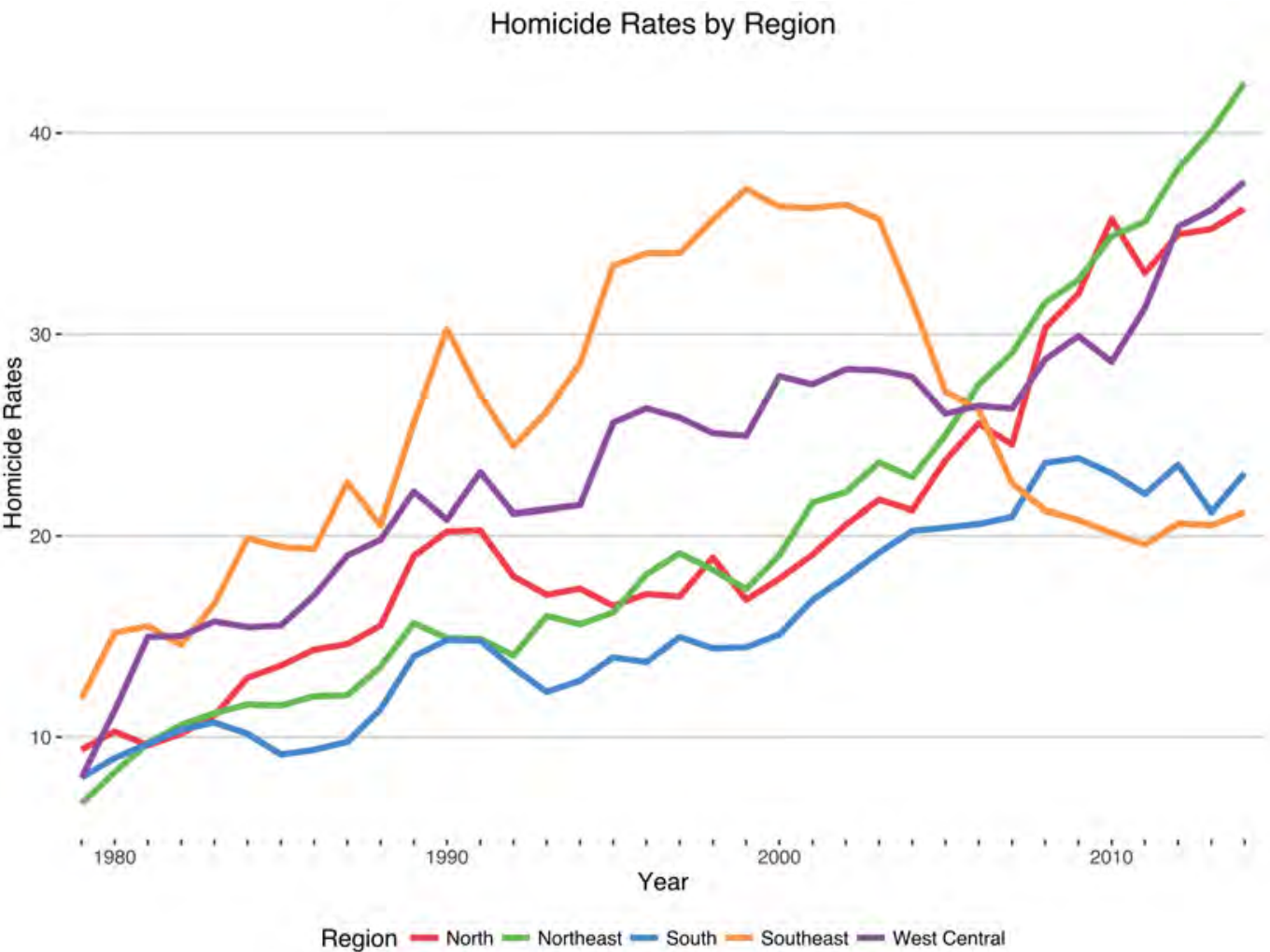

Figure 1.1: Homicide Rates by Region from 1979 to 2014

Notes: Data on homicide rates is provided by Datasus' SIM. We sum homicides in each region and divide it by the sum of its population divided by a hundred thousand. 


\section{2}

\section{Related Literature and Contribution}

Our work relates to the literature on conflicts in the absence of state presence and violence generated by the growth of drug markets $(40,41,42,44$, 43). Moreover, this work deals with the question of whether the emergence of additional contested resources generates violent behavior. It is unclear which direction this effect might take. (38) show two potential effects in opposite directions, the first is a rapacity effect where temptation to prey on others generates more violence $(46,47,48,45)$. On the other hand, additional resources generate better wages and it may raise the opportunity cost of violence $(31,40,49)$.

We show that the emergence of drug markets generates an increase in violence. This effect is more pronounced among young males killed by fire weapons, and it stabilizes at a high level in the long run. We also provide evidence the that lack of state presence augments the effects of drug markets. These results contribute to the literature on resource booms and violence $(47,50,7,52,53)$. The literature on the organization of drug markets tells us that the mere presence of those markets is not necessarily associated with violence $(32,37,20)$. At the same time, (59) tell us that violence is not inherently linked to the presence of favelas(slums). We show results indicating that the presence of slums may make the effect of drug markets on violence stronger.

There are several works explaining the pattern of homicides observed in the Brazilian context. For instance, (34) show that for the São Paulo Metropolitan Area (SPMA) the adoption of dry laws, which limits alcohol sales on specific hours of the week, reduced homicides. (35) provide evidence that a nationwide anti-firearm legislation, which decreased the amount of firearms in circulation, caused a reduction on homicides. (36) show evidence that the change in age structure seen in SPMA was the main determinant for the rise and fall in crimes observed in the 1990's and 2000's. We complement these by providing a look on how the Brazilian experience with violence in the 2000's could be associated with the emergence of drug markets nationwide.

This work is also related to the literature on the emergence of crack cocaine in the US during the 1980's and 1990's. (9) use a variety of measures 
for crack cocaine use, including drug hospitalizations, to create an index of exposure on US main metropolitan areas. The findings suggest that more exposure to crack cocaine led to more violence. With similar results, (10) use data on drug hospitalizations and information from the police to measure when crack cocaine entered US metropolitan areas. Our work expands this literature by showing results from the Brazilian experience using data that encompass a larger period and greater magnitude geographically. 


\section{3}

\section{Is drug entry associated with violence?}

In this section we examine the link between the emergence of drug markets (drug entry), among Brazilian municipalities, and violence, for the period from 1998 to 2013. We first describe the data and explain the empirical strategy, and then discuss the results.

\section{1}

\section{Data}

To assess our main question, we analyze data by municipality using two datasets. They are provided by SUS, Brazil's publicly funded health care system, thorough their Information Department (Datasus). The first one is the Sistema de Informações sobre Mortalidade (SIM), which gives information on mortality in general going from 1979 to 2014 . The data on homicides come from this dataset. We use all the cases with icd-10 codes X85-Y09, which means that we group together homicides committed in various forms, not only with fire weapons, but also with cutting objects, concussion and so forth. We will use subclassifications of homicides, with and without fire weapons, to establish which types of homicide are being more affected by the drug market. These data are collected in two steps: 1 . The medical examiner involved in the case indicates the cause of death and, if it was natural death, but death by external causes, the case is sent to the Legal Medical Institute $(I M L)$. 2. The medical examiner collects more information, for example: from the expert examiner, police and family. The medical examiner then establishes if the death was by homicide, suicide or undetermined. Moreover, the coroner indicates which instrument was used, e.g. fire weapon, knife, poison.

The data for homicides carry some measurement error. (13) argues that the collection of this data is far from satisfactory. For example, his work shows that, in the state of Rio de Janeiro, deaths by undetermined causes rose in the end of the 2000's in a particularly non-random way. This was accompanied by the fact that homicides were falling in the same period, which means that part of the reason why homicides fell could have just been a statistical illusion produced by classifying homicides as undetermined causes. We do not expect this error to vary when drug gangs enter a municipality. And if the reporting 
of deaths change in a biased way, it favors the coverage of violent deaths so our estimates of drug entry would be biased towards not finding effects.

The second dataset provided by Datasus is the Sistema de Informações Hospitalares $(\mathrm{SIH})^{1}$. It is used by the government to administer the payment of hospitalizations and to control expenses in the public health system. The data on drug-related hospitalizations come from this dataset ${ }^{2}$. Hospitals must send a document for each procedure adopted to the central government that will transfer resources related to the medical procedures. This document contains information on which procedure was carried, and also on the causes of the illness (identified by an ICD-10 code), characteristics of the patient, and expenditure.

It's important to notice that there are three overly represented categories of hospitalization by drug use in this database: alcohol use, cocaine use and multiple drug use. They represent $70 \%, 6.5 \%$ and $21 \%$ of the hospitalization cases respectively. Although it is possible that the multiple drug case encompasses alcohol use, the results do not change when we include only cocaine use. We will be using data on cocaine and multiple drugs throughout the work.

From the previous dataset, on hospitalizations due to drug use, we construct our measure of drug entry. We apply a rule whereby municipalities that overcome a certain cutoff are presumed to have had drug entry from then on. Since the specific cutoff is arbitrary, we present results for a variety of cutoffs and choose one as our preferred cutoff. We will be using a cutoff of 10 drug cases to describe the data, which be further explained in the next section. To sum up, we assume that drug entry takes place when a sudden large spike in hospitalization occurs.

\subsection{1}

\section{Description of Drug Entry}

According to the World Bank Report (24), Brazil's internal drug market has rapidly grown during the 2000's. For example, during the 1998-2014 period it reports that "in Brazil, the increase in the quantity of cocaine seized was attributable to a combination of improved law enforcement efforts, the growing domestic market for cocaine and increasing cocaine shipments to overseas markets". Furthermore, (11) estimate, using a national survey for the year 2013, that $2.2 \%$ of the population (excluding the elderly) had used crack-

\footnotetext{
${ }^{1}$ Micro data for this database and, for the SIM database, is possible to download from $\mathrm{ftp}: / / \mathrm{ftp}$.datasus.gov.br/dissemin/publicos/

${ }^{2}$ We will be using all hospitalizations carrying icd-10 codes F10-F19. It was noticed that icd-10 codes T36-T50 are for poisoning by drugs while F10-F19 is for mental and behavioral disorders. We could not find any case for the first codes, T36-T50.
} 
cocaine in the the previous year. We present a description of our measure of drug entry to show that we truly capture this trend of increased use of drugs.

Figure 3.1 shows the number of municipalities in which drug hospitalization has surpassed the cutoff of at least 10 cases per year. We observe an increase in the number of municipalities where drugs have entered going from $210(3.8 \%)$ in 1998 to $1360(24.7 \%)$ in $2013^{3}$. This mirrors the trends on drug use described below, with the addition of stating that drug use is also expanding to new municipalities where it was not previously observed.

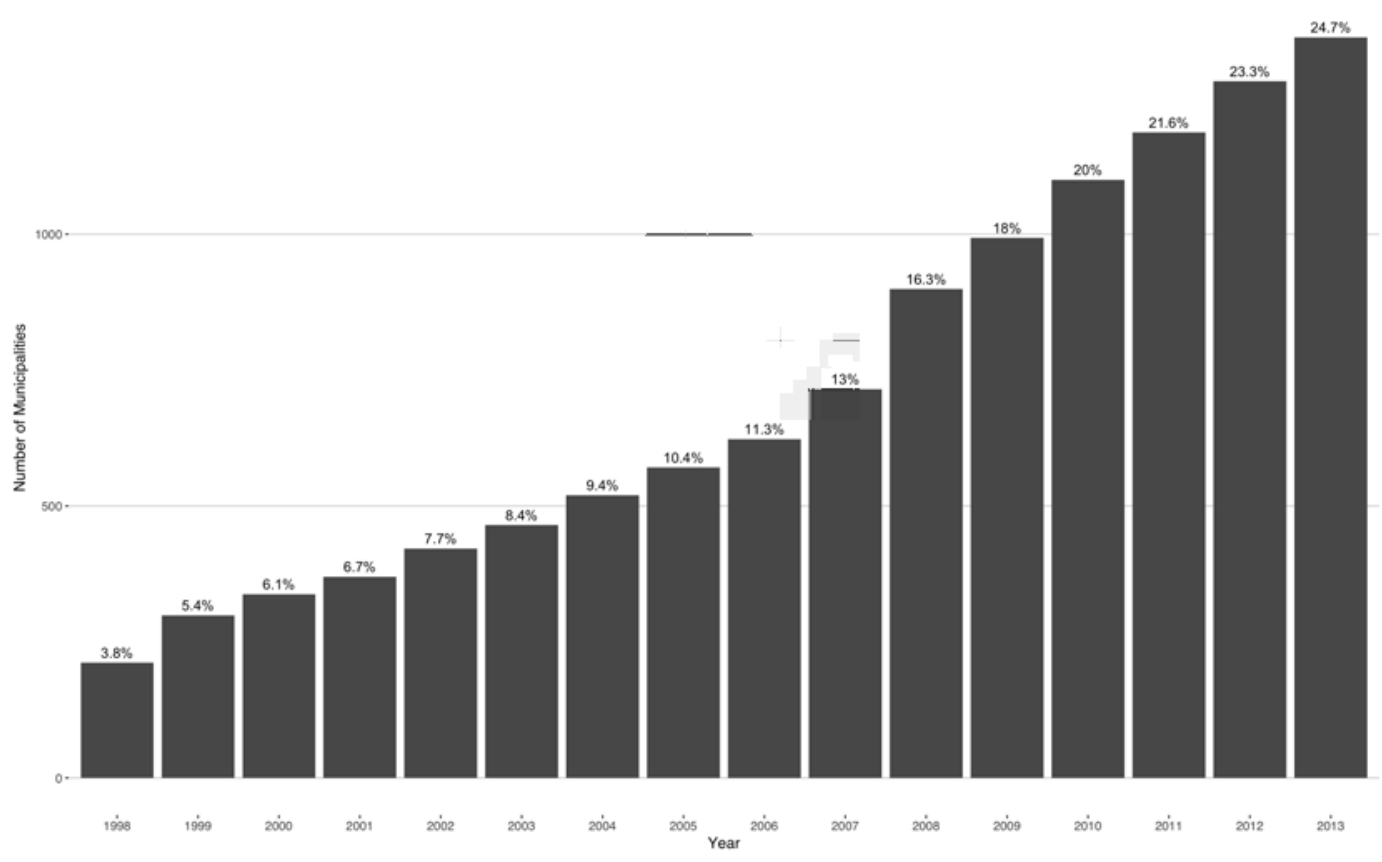

Figure 3.1: Municipalities where at least 10 hospitalizations due to drug use occurred from 1998 to 2013

Notes: We consider that drug entry happened when a given municipality experienced a level of hospitalization due to drug use greater than 10 cases in any period before that year. The y-axis represents the number of municipalities where drug entry happened while the percentage on top of each bar represents the proportion of municipalities where drug entry happened. Hospitalizations due to drug use are every case where the primary cause has icd-10 codes F11-F19.

In addition to showing the growing number of municipalities where drugs entered, it is interesting to show the territorial distribution of those new municipalities. If we believe that the rise of drug markets is a Brazilian problem, we should see drug presence spreading throughout the country. This is important since we need variation to be fairly distributed throughout

${ }^{3}$ For the 1 case cutoff those numbers are, from $1352(24.5 \%)$ to $4894(88.8 \%)$. For the 4 case cutoff, from $446(080.9 \%)$ to $2656(48.2 \%)$. For the, from 16 case cutoff $154(2.7 \%)$ to $942(17.1 \%)$ 
the country to identify the effects of drug markets on the average Brazilian municipality. In Figures 3.2 and 3.3 we show in green municipalities where drug entry has occurred for the years 2000 and 2012. The expansion of drug entry is national and widespread, representing all Brazilian 5 regions and 27 states.

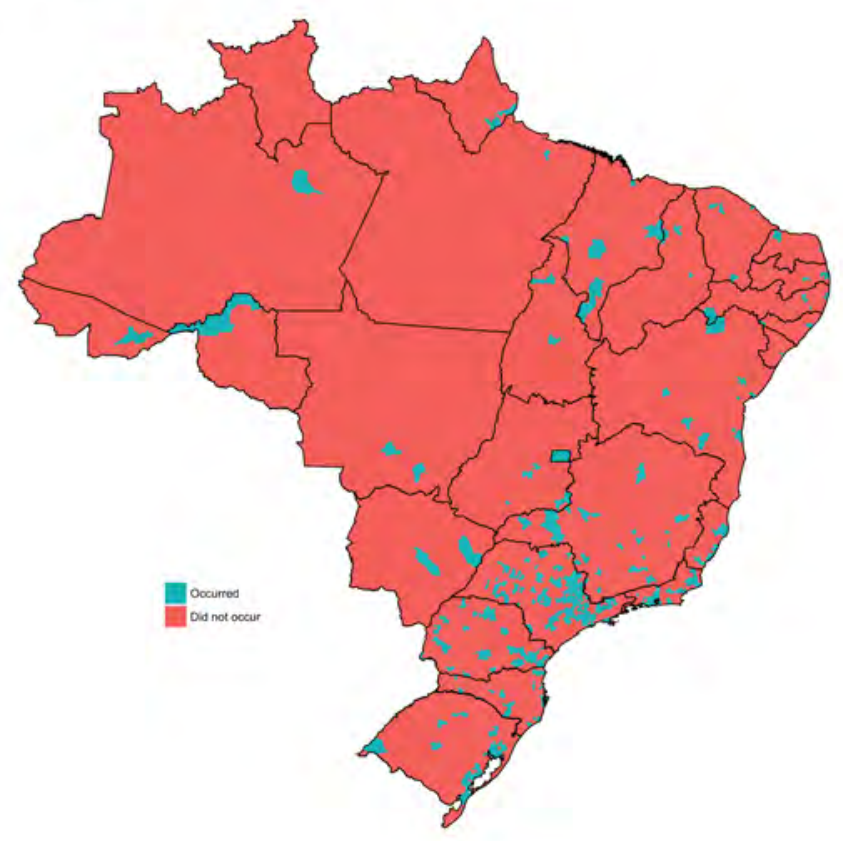

Figure 3.2: Drug Entry by Municipality - 2000

Notes: A municipality is shown in green when drug entry happened. We consider that drug entry happened when a given municipality experienced a level of hospitalization due to drug use greater than 10 cases in any period before that year. Hospitalizations due to drug use are every case where the primary cause has icd-10 codes F11-F19. 


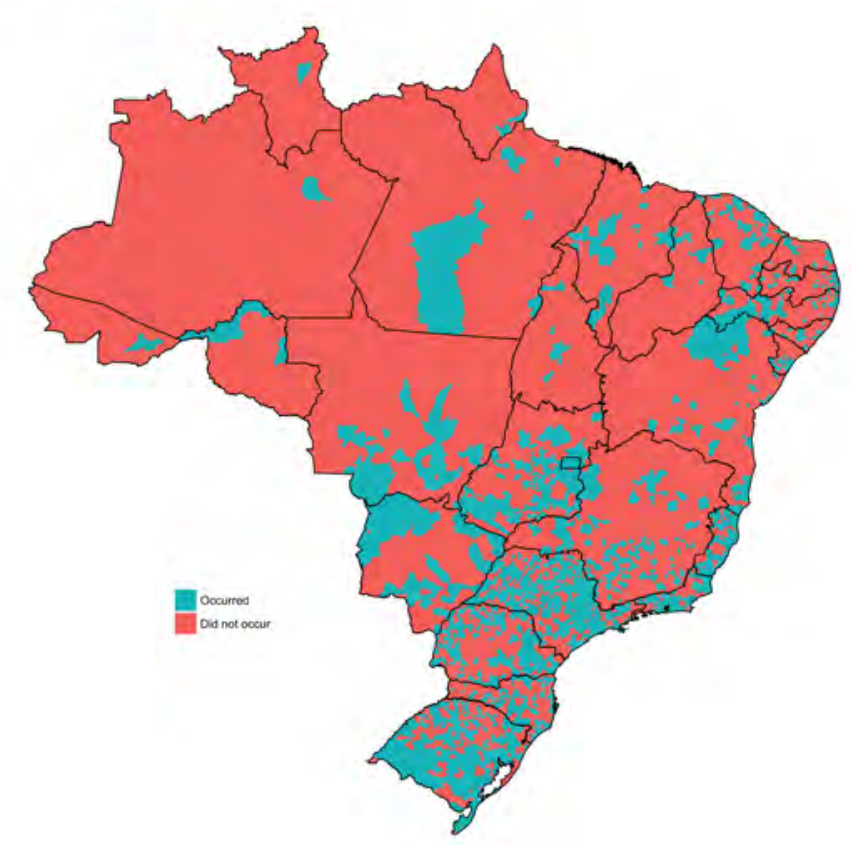

Figure 3.3: Drug Entry by Municipality - 2012

Notes: A municipality is shown in green when drug entry happened. We consider that drug entry happened when a given municipality experienced a level of hospitalization due to drug use greater than 10 cases in any period before that year. Hospitalizations due to drug use are every case where the primary cause has icd-10 codes F11-F19.

\section{2}

\section{Empirical Strategy}

We explore the fact that drug markets have emerged at different moments in time among Brazilian municipalities. This variation gives us the possibility of estimating the potential increment in violence followed by drug entry.

The construction of the variable representing drug entry is presented as follows. Let $o_{i, s, t}$ be hospitalizations due to drug use, $i$ the municipality, $s$ the state, and $t$ the year, then drug entry is $D_{i, s, t}=\mathbb{1}\left\{o_{i, s, \tau} \geq k ;\right.$ for any $\left.\tau \leq t\right\}$ where $k$ is the chosen cutoff necessary for drug entry. Therefore, we consider that after drug entry there is no coming back to a state where drug markets are not present. Furthermore, we are interested in explaining the expected homicide rate in municipality $i$, state $s$, during month $t, h_{i, s, t}$, as a function of municipality fixed effects, time effects, and drug entry, $D_{i, s, t}$. We also add statespecific linear trends, $t \times \gamma_{s}$, as Brazilian states carry most of the responsibility for public security policy, and this might be affecting both violence and drug entry.

The selection of a specific cutoff is very important here. If we choose a cutoff that is too low, we may be capturing too much noise, specially in 
smaller municipalities, since hospitalization of only a few people might not be indicative of the presence of drug markets. On the other hand, a cutoff too high may be indicating an already grown market for drugs, so that we will be capturing the effects of going from a small to large-sized drug market. What we want to capture is the effect of drug markets in places where drug activity was too little to be noticed, but after a period of time became apparent. Since we do not have a clear way of choosing the "right" cutoff, we will test results for a variety of cutoffs and choose one as our preferred.

We estimate the effect of drug entry on violence using 3 different estimation methods: OLS, Poisson, and a Log transformed OLS. In the first method, represented by Equation 3-1, we use a linear model without dealing with the potential distributional problems carried by the dependent variable, homicide rate. We include $\alpha_{i}$ to control for all characteristics constant throughout the years, and $\delta_{t}$ for effects common to all municipalities in a given year. The term $t \times \gamma_{s}$ captures variation in time for municipalities in the same state.

$$
\mathbf{E}\left(h_{i, s, t}\right)=\alpha_{i}+\delta_{t}+t \times \gamma_{s}+\beta D_{i, s, t}
$$

Second, we estimate a Poisson regression as represented in Equation 32 , following (39) and (38). Thus, we are able to deal with the fact that our dependent variable has a large mass at zero, and treat it as a count variable. We include the population variable with coefficient set to 1 to better compare with the results for the OLS cases.

$$
\mathbf{E}\left(h_{i, s, t}\right)=\alpha_{i} \delta_{t} \exp \left(\beta D_{i, s, t}+t \times \gamma_{s}\right)
$$

Lastly, in Equation 3-3, we estimate a linear model with a log transformation to account for the large mass at the zero value. Following the same method as in (38), we add the constant $r>0$ equal to the 50th percentile ${ }^{4}$. Moreover, we interpret estimates of the coefficient $\beta$ as semi-elasticities after multiplying them by the sample average of $\frac{h_{i, t}+r}{h_{i, t}}$.

$$
\mathbf{E}\left(\ln \left(h_{i, s, t}+r\right)\right)=\alpha_{i}+\delta_{t}+t \times \gamma_{s}+\beta D_{i, s, t}
$$

We choose a cutoff of 10 hospitalization cases as our preferred way to measure drug entry so that after a given municipality passes this cutoff we consider that drug markets are present thereafter. Results for cutoffs slightly below and higher than 10 cases still hold. For cutoffs closer to 1, the results become very sensitive to the inclusion of state trends, and in some cases becoming negative. Therefore, we argue that our preferred measure is more

${ }^{4}$ In their case, they use the 90th percentile. As it was done in their case, we also test for different percentiles with no significant change on the results 
robust regarding the inclusion of controls, and proceed using it throughout the work ${ }^{5}$.

Our identification comes from the timing of drug entry on different municipalities. We add state-specific linear trends $t \times \gamma_{s}$, since, as was noted previously, public security policy is decided at the state level. By doing this, we also control regional characteristics such as the proximity to producing countries or the possibility of becoming a hub for international drug trade that could be affecting both violence and drug entry. Thus, $\beta$ is identified by comparing how the different timings in drug entry increase homicide rates for municipalities in the same state.

On estimates of Equations 3-1 and 3-3 we use homicides per hundred thousand people as a dependent variable. In the Poisson estimates, we use homicides and include population as exposure. We also use population weights in all regressions to deal with larger variance in homicide rates for lower population municipalities.

Moreover, we explore the fact that we have variation in the timing of drug entry between municipalities to estimate the effect before and after drug entry for multiple periods of time. We present below a representation of the regression when we transform based on equation 3-1, following (54).

$$
\mathbf{E}\left(h_{i, s, t}\right)=\alpha_{i}+\delta_{t}+t \times \gamma_{s}+\sum_{k=-5}^{4} \beta_{k} D_{i, s, t}+\beta_{5+} D_{i, s, t}
$$

We have 2 reasons to estimate Equation 3-4. First, the nature of the data prevents us from testing the parallel trends assumption before the treatment, since drug entry occurs on different time periods. Thus, we can test whether, prior to drug entry, coefficients $\beta_{-5}$ to $\beta_{0}$ are insignificant to verify the parallel trends assumption. Then, we compare treatment and control groups before drug entry. Second, we can explore how the effect of drug entry evolves through time. It could increase exponentially, stabilize, or go back to a level prior to drug entry.

\section{3 \\ Results}

We estimate the regressions proposed on the previous question in order to provide evidence on the link between drug entry and violence. The two main opposing effects we have in mind are the rapacity effect and the opportunity cost effect. The first tells us that additional resources provide incentives for

\footnotetext{
${ }^{5}$ We present in the appendix results for a variety of cutoffs. The OLS estimates are very sensitive to the inclusion of state trends at lower cutoffs, while when using Poisson regression, estimates are more robust.
} 
violent behavior. When state presence is lacking, agents may engage in violence in order to capture those resources. The other tells us that new resources could increase wages, and drive the opportunity cost of fighting higher. We show evidence that the first effect is stronger.

One last consideration, before showing the results, is that, in the Brazilian case, there is no national dataset exploring the context in which homicides occur. This means that, we cannot know from our dataset (or any other) if homicides are related to drug markets or not. Furthermore, we know from anecdotal evidence that homicides occurring in drug markets could have a number of reasons: traffickers fighting against each other (or the police), debt enforcement from buyers, and even revenge from a previous disagreement. For instance, (66) reports, using data from Rio de Janeiro's Instituto de Segurança Pública, that in the state of Rio de Janeiro, one third of the homicides can be traced back to drug traffickers. From those, only a fraction is linked to fights between rival gangs. A significant portion of homicides is related to the enforcement of debt payment and battles with the police.

We present in Table 3.1 results for the effect of drug entry on violence. In columns (1) and (2) we present results for OLS regressions; in columns (3) and (4) for Poisson regressions and columns (5) and (6) for the Log transformed OLS regressions.

In Column (1) we show a positive and significant association between drug entry and violence. We estimate that after drug entry there is a 4.2 increase, on average, in homicide rates. In terms of the average municipality this means a rise of $32 \%$ in homicide rates. In Column (2) we show results after further controlling for state-specific linear trends. As it was mentioned before, this is particularly important because, for instance, public security policy is organized at the state level. Another potential reason for the inclusion of state trends is that certain regions experienced different trends in violence. States on the Southeast Region of Brazil experienced a rapid rise on homicide rates during the 1990's. In this case, we estimate that the average municipality homicide rate rises by $25 \%$ after drug entry (3.27 point estimate). In column (3) we present Poisson estimates of $26 \%$ of marginal effect, while in column (4), when adding controls for state-specific linear trends, the estimate falls to $16 \%$. Finally, columns (5) and (6) show estimates for the log transformed model of an increase in $17 \%$ and, including state trends, $13.5 \%$.

These findings go in the direction of the rapacity effect. When drug markets emerge they generate an increase in violence. As was previously discussed, it is important to note that homicides are not identified by their motivation. Thus, we cannot say if violent behavior is associated with drug 
traffickers preying on each other and defending themselves. In the next sections, we show evidence that the rise in violence associated with drug entry may be related with drug markets. But first, we show the dynamic of the effect described above by estimating Equation 3-4. Furthermore, our understanding is that using these different models does not change results significantly. We continue our analysis focusing on our preferred models in columns (2) and (6).

Table 3.1: Is drug entry associated with violence?

\begin{tabular}{lcccccc}
\hline \hline & \multicolumn{5}{c}{ Dependent Variable: Homicide Rate } \\
\cline { 2 - 7 } & $(1)$ & $(2)$ & $(3)$ & $(4)$ & $(5)$ & $(6)$ \\
\hline Drug Entry & $4.177^{* * *}$ & $3.270^{* * *}$ & $0.201^{* *}$ & $0.113^{* * *}$ & $0.170^{* * *}$ & $0.135^{* * *}$ \\
& $(0.223)$ & $(0.188)$ & $(0.087)$ & $(0.026)$ & $(0.011)$ & $(0.010)$ \\
& & & & & & \\
\hline Marginal Effect & - & - & $22 \%$ & $12 \%$ & & - \\
Effect on Mean & $32 \%$ & $25 \%$ & - & - & - & - \\
Mean Dep Var & 13.25 & 13.25 & 13.25 & 13.25 & & $\mathrm{Y}$ \\
Year FE & $\mathrm{Y}$ & $\mathrm{Y}$ & $\mathrm{Y}$ & $\mathrm{Y}$ & $\mathrm{Y}$ & $\mathrm{Y}$ \\
State Trend & $\mathrm{N}$ & $\mathrm{Y}$ & $\mathrm{N}$ & $\mathrm{Y}$ & $\mathrm{N}$ & $\mathrm{Y}$ \\
Observations & 88,112 & 88,112 & 88,112 & 88,112 & 88,112 & 88,112 \\
$\mathrm{R}^{2}$ & 0.621 & 0.740 & 0.846 & 0.849 & 0.647 & 0.734 \\
\hline \hline
\end{tabular}

Note: This table shows the association between drug entry and violence. The dependent variable is Homicide Rates by municipality as measured by Datasus SIM - Sistema de Informação sobre Mortalidade - comprising icd-10 codes X85x-X99x. Drug entry is measured as the dummy variable which 1 if hospitalizations due to drug use suddenly passes the cutoff of 10 drug cases. Columns differ in which model is used. All regressions use population weights. ${ }^{* * *} \mathrm{p}<0.01{ }^{* *} \mathrm{p}<0.05^{*} \mathrm{p}<0.10$

\subsection{1}

\section{Dynamic of the relation between drug entry and violence}

We argued in the previous section that the effect of drug entry on homicide rates was positive and significant. Furthermore, we can analyze the dynamics of this effect. Drug entry might be affecting violence differently in the short and long run. We want to be able to tell how quickly homicide rates grow after drug entry, and if it stabilizes, mean reverses or grows exponentially. To test this, we estimate a variation of the models on Equations 3-1, represented by Equation 3-4, and similarly, a version of Equation 3-3 with 5 lags and 5 leads.

We show in Figure 3.4 both estimations. On the left panel, we present the estimates for the estimation of the model in Equation 3-4, and on the right panel we show estimates for the version of the model of Equation 3-3 with lags and leads. First, we can see that, in the left panel, the estimates are not 
significant for the previous, except for 2 years before drug entry. This indicates that the treatment and control groups are balanced. Homicide rates gradually rise, starting in the first year of drug entry, and stabilizes at a long-run level of 4.2. The log transformed model, on the right, is more difficult to interpret, since the effects are present before drug entry. This may be a problem created by the transformation. However, we can observe that homicide rates start to rise sharply after the entrance of drugs.

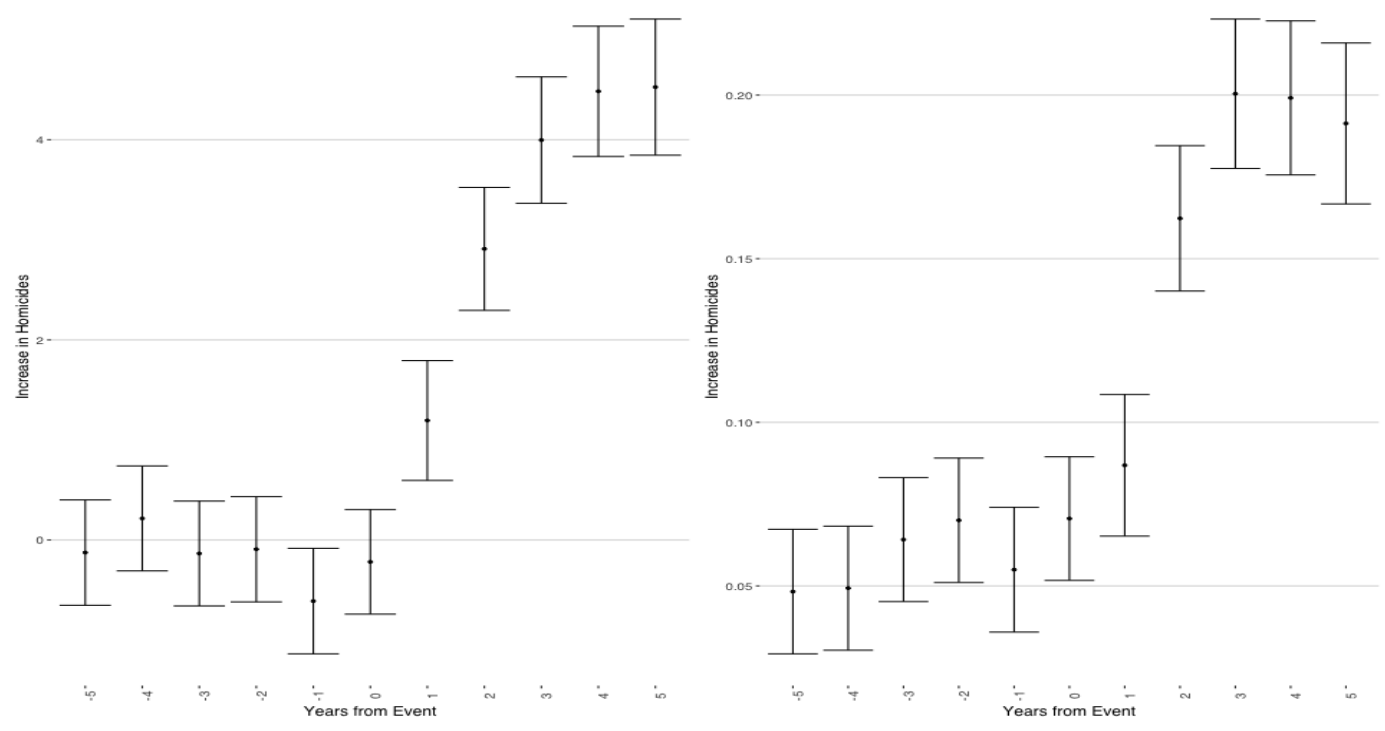

Figure 3.4: The dynamic of the relation between drug entry and violence

Notes: We show the estimates for the coefficients in the regression of homicide rates on drug entry and fixed effect for municipalities and time, and state-specific linear trend. We interact the drug entry variable with a time dummy variable for the 6 five years before the event and 5 five years after. Confidence intervals has significance level of $95 \%$.

\section{4}

\section{Robustness Checks}

In this section we show estimates for different specifications of the model exemplified in Equation 3-1, in order to test for the robustness of the results.

We start by showing on columns (1) and (2), of Table 3.2, the results regarding the tendency of urban centers to be more violent. There is a vast literature discussing this tendency (57). If drug entry was being driven by a large population, our results would be biased upwards. Thus, we add a control variable for population in the first column. Moreover, in the second column, we add a dummy variable if the municipality is the capital of the state interacted with a linear trend. This is an indicative of urban centers, since in Brazil the largest population municipalities (and the urban centers) in a given state 
happen to be also the capital. Results change only slightly from our preferred estimate shown in column (2) of Table 3.1.

On column (3), we control for the population of young people in the municipality. Here, we follow works that find a larger tendency for young people to present violent behavior. Again, if drug consumption is related to the a larger youth population, drug entry should be affected by this variable. The estimates change downwards, but the interpretation of our main results still holds.

Table 3.2: Robustness Checks

\begin{tabular}{lccccc}
\hline \hline & \multicolumn{5}{c}{ Dependent Variable: Homicide Rate } \\
\cline { 2 - 6 } & $(1)$ & $(2)$ & $(3)$ & $(4)$ & $(5)$ \\
\hline Drug Entry & $2.656^{* * *}$ & $3.452^{* * *}$ & $2.457^{* * *}$ & $0.889^{* * *}$ & $3.279^{* * *}$ \\
& $(0.189)$ & $(0.228)$ & $(0.188)$ & $(0.235)$ & $(0.185)$
\end{tabular}

Population by $100,000 \quad-0.769^{* * *}$

$(0.031)$

Young Pop by 10,000

$0.731^{* * *}$

$(0.019)$

\begin{tabular}{lccccc}
\hline Year FE & Y & Y & Y & Y & Y \\
State Trend & Y & N & Y & N & Y \\
State Quad. Trend & N & N & N & N & Y \\
Munic. Trend & N & N & N & Y & N \\
Capital Trend & N & Y & N & N & N \\
Observations & 88,112 & 88,112 & 88,112 & 88,112 & 88,112 \\
$\mathrm{R}^{2}$ & 0.741 & 0.623 & 0.744 & 0.819 & 0.750 \\
\hline \hline
\end{tabular}

Note: This table shows robustness checks for the association between drug entry and violence. The dependent variable is Homicide Rates by municipality as measured by Datasus SIM - Sistema de Informação sobre Mortalidade - comprising icd-10 codes $\mathrm{X} 85 \mathrm{x}-\mathrm{X} 99 \mathrm{x}$. Drug entry is measured as the dummy variable which 1 if hospitalizations due to drug use suddenly passes the cutoff of 10 drug cases. Colums(1) adds population as a control variable. Columns(2) adds capital-specific linear trends. Column (3) adds young population variables. Column (4) adds municipality-specific linear trends and Column (5) adds quadratic trends. All regressions use population weights. ${ }^{* * *} \mathrm{p}<0.01$ $* * \mathrm{p}<0.05 * \mathrm{p}<0.10$

We show in column (4) the results when adding municipality-specific linear trends. In this case, estimates drop sharply, although we can argue that most of the signal is being lost. This happens due to the loss of withingroup variation when comparing in such a small unit, which in this case is the municipality itself. We also show the results, in column (5), when adding 
state-specific quadratic trends. The results vary minimally, showing that linear trends for each state is enough.

Lastly, we show on Tables A.1 - A.6 estimates for different cutoffs. As we argued before, when cutoffs are too low we might be capturing too much noise. This is true if, for lower population municipalities, a small spike in hospitalizations due to drug use may not be an indicative of an active drug market. If the cutoff is too high, we might be losing a rise in hospitalizations that potentially informs about drug entry. For lower cutoffs, the results for Equation 3-1 are very sensitive to the inclusion of state-specific trends. In the Log transformed model, as cutoffs values get higher, estimates fall, becoming negative for higher levels. In the Poisson model,the results do not vary much for different values of the cutoff.

We believe that for cutoffs close to 10 hospitalizations estimates are robust for all the models. 


\section{4 \\ Heterogeneity}

In this chapter, we explore the heterogeneity of the estimates from the previous chapter.

\section{1}

Which groups suffer more with the violence rise from drug entry?

We discussed is the previous chapter that, for our data, we are not able to observe the motivations for homicides. This complicates the interpretation of our findings, since we cannot estimate the association between drug entry and violence using only homicides related to drug markets. Furthermore, we explained that, even in the context of drug markets, the motivations for homicides might not be related to drug traffickers fighting for resources: territory, drugs, weapons, debt payment. However, we can explore the characteristics of people involved in homicides. By doing this, we are able to show how stronger is the association between violence and drug entry for different portions of the population.

The link between the motivation behind homicides and the characteristics of people being killed is not clear. As far as we know, no work explores this relationship. However, there are works that describe the characteristics of individuals involved in drug markets $(55,56)$. Thus, we subdivide homicides from these characteristics and explore the heterogeneity of the association between drug entry and violence. In exploring the estimates for different groups, we are also able to confirm that our measure of drug entry is plausible. If any other group that should not be associated with drug markets in fact is associated, then we should be doubtful about this measure of drug entry.

To be more specific, we compare results for pairings of groups, when one is expected to be more impacted by drug markets. Those pairings are: men/women, young/non-young and homicides committed with/without fire weapons. The first groups of the pairings should be more affected by drug markets.

We also look at the dynamic of the effect when dissecting the homicide variables into groups. This is done in the same way as in Figure 3.4, using the models on Equations 3-1 and 3-3. 
We show in Tables 4.1 and 4.2 the results for OLS and Log transformed OLS estimates of drug entry on violence for different groups of people and types of violence. These are intended to represent sections of the population which should be more affected by an expanding drug market. On both Tables, Columns (2) and (3) present homicides rates for young (people aged 16-24) and non-young people, respectively. Column (3) subgroups into homicide rates for fire weapons, while column (4) refers to rates without fire weapons. And finally, columns (6) and (7) show the results for homicide rates against men and women, respectively. Thus, we seek to find out whether drug entry is associated with an increase in violence against young males with the use of fire weapons.

In Table 4.1, we show how the magnitude of the estimates for groups predicted to be most affected by drug entry - even-numbered columns - differs in relation to their opposite groups - odd-numbered columns. In column (2), we estimate that, when drug entry happens, young homicide rates rise by $33 \%$ from the mean against an impact of $19 \%$ on non-young people, in column (3). In the case of homicides committed with fire weapons, column (4) estimates an impact of $30 \%$, while column (5), estimates an impact of $16 \%$ for violence commited without fire weapons. Finally, column (7) presents results for homicides against men, with an increase of $35 \%$ from the mean against $12 \%$ for women, which is shown in column (8). Estimates for the Log transformed model in Table 4.2 show similar results.

Our results show that the portions of the population that are predicted to be most affected by the emergence of drug markets are the ones being most associated with our measure of drug entry. These results also point to the direction that our variable truly captures the timing of drug entry.

The estimates for the version of the model with lags is shown in Figure 4.1, where we are able to observe the dynamics. For the pairs young/nonyoung and men/women, the same dynamic seen in the last exercise is observed. We see trends rising in the subsequent years after the event, stabilizing at a high level in the long run. The surprising result comes from the fact that, in the first year after the event, homicide rates without fire weapons rise sharply and fall in the years after, while homicide rates with fire weapons increase slowly throughout the years. This may evidence that, as violence escalates, people start to use more fire weapons in order to defend themselves or to attack others more effectively. 
Table 4.1: Is the association between drug entry and violence stronger for some groups?

\begin{tabular}{lccccccc}
\hline \hline & \multicolumn{7}{c}{ Dependent Variable: Homicide Rate } \\
\cline { 2 - 8 } & Full & Young & Non-Young & Fire Weapon & No FW & Men & Women \\
& $(1)$ & $(2)$ & $(3)$ & $(4)$ & $(5)$ & $(6)$ & $(7)$ \\
\hline Drug Entry & $3.270^{* * *}$ & $6.536^{* * *}$ & $2.280^{* * *}$ & $2.412^{* * *}$ & $0.858^{* * *}$ & $6.180^{* * *}$ & $0.341^{* * *}$ \\
& $(0.188)$ & $(0.495)$ & $(0.160)$ & $(0.162)$ & $(0.087)$ & $(0.338)$ & $(0.082)$ \\
& & & & & & & \\
\hline Effect on Mean & $25 \%$ & $33 \%$ & $19 \%$ & $30 \%$ & $16 \%$ & $35 \%$ & $12 \%$ \\
Mean Dep Var & 13.25 & 19.63 & 11.81 & 7.93 & 5.33 & 17.8 & 2.83 \\
Year FE & $\mathrm{Y}$ & $\mathrm{Y}$ & $\mathrm{Y}$ & $\mathrm{Y}$ & $\mathrm{Y}$ & $\mathrm{Y}$ & $\mathrm{Y}$ \\
State Trend & $\mathrm{Y}$ & $\mathrm{Y}$ & $\mathrm{Y}$ & $\mathrm{Y}$ & $\mathrm{Y}$ & $\mathrm{Y}$ & $\mathrm{Y}$ \\
Observations & 88,112 & 88,112 & 88,112 & 88,112 & 88,112 & 82,605 & 82,605 \\
$\mathrm{R}^{2}$ & 0.740 & 0.717 & 0.654 & 0.756 & 0.403 & 0.790 & 0.244 \\
\hline \hline
\end{tabular}

Note: This table shows the association between drug entry and violence for different groups. The dependent variable is Homicide Rates by municipality as measured by Datasus SIM - Sistema de Informação sobre Mortalidade - comprising icd-10 codes X85x-X99x. Drug entry is measured as the dummy variable which 1 if hospitalizations due to drug use suddenly passes the cutoff of 10 drug cases. Columns differ in which group is being subset. All regressions use population weights. ${ }^{* * *} \mathrm{p}<0.01 * * \mathrm{p}<0.05 * \mathrm{p}<0.10$

Table 4.2: Is the association between drug entry and violence stronger for some groups? (Log transformed model)

\begin{tabular}{lccccccc}
\hline \hline & \multicolumn{7}{c}{ Dependent Variable: $\log ($ Homicide Rate $)$} \\
\cline { 2 - 8 } & Full & Young & Non-Young & Fire Weapon & No FW & Men & Women \\
& $(1)$ & $(2)$ & $(3)$ & $(4)$ & $(5)$ & $(6)$ & $(7)$ \\
\hline Drug Entry & $0.135^{* * *}$ & $0.165^{* * *}$ & $0.111^{* * *}$ & $0.140^{* * *}$ & $0.117^{* * *}$ & $0.142^{* * *}$ & $0.068^{* * *}$ \\
& $(0.010)$ & $(0.013)$ & $(0.010)$ & $(0.011)$ & $(0.011)$ & $(0.011)$ & $(0.012)$ \\
& & & & & & & \\
\hline Mean Dep Var & 13.25 & 19.63 & 11.81 & 7.93 & 5.33 & 17.8 & 2.83 \\
Year FE & $\mathrm{Y}$ & $\mathrm{Y}$ & $\mathrm{Y}$ & $\mathrm{Y}$ & $\mathrm{Y}$ & $\mathrm{Y}$ & $\mathrm{Y}$ \\
State Trend & $\mathrm{Y}$ & $\mathrm{Y}$ & $\mathrm{Y}$ & $\mathrm{Y}$ & $\mathrm{Y}$ & $\mathrm{Y}$ & $\mathrm{Y}$ \\
Observations & 88,112 & 88,112 & 88,112 & 88,112 & 88,112 & 82,605 & 82,605 \\
$\mathrm{R}^{2}$ & 0.734 & 0.720 & 0.664 & 0.771 & 0.453 & 0.777 & 0.370 \\
\hline \hline
\end{tabular}

Note: This table shows the association between drug entry and violence for different groups. The dependent variable is $\log$ (Homicide Rates) by municipality as measured by Datasus SIM - Sistema de Informação sobre Mortalidade - comprising icd-10 codes X85x-X99x. Drug entry is measured as the dummy variable which 1 if hospitalizations due to drug use suddenly passes the cutoff of 10 drug cases. Columns differ in which group is being subset. All regressions use population weights. ${ }^{* * *} \mathrm{p}<0.01 * * \mathrm{p}<0.05 * \mathrm{p}<0.10$

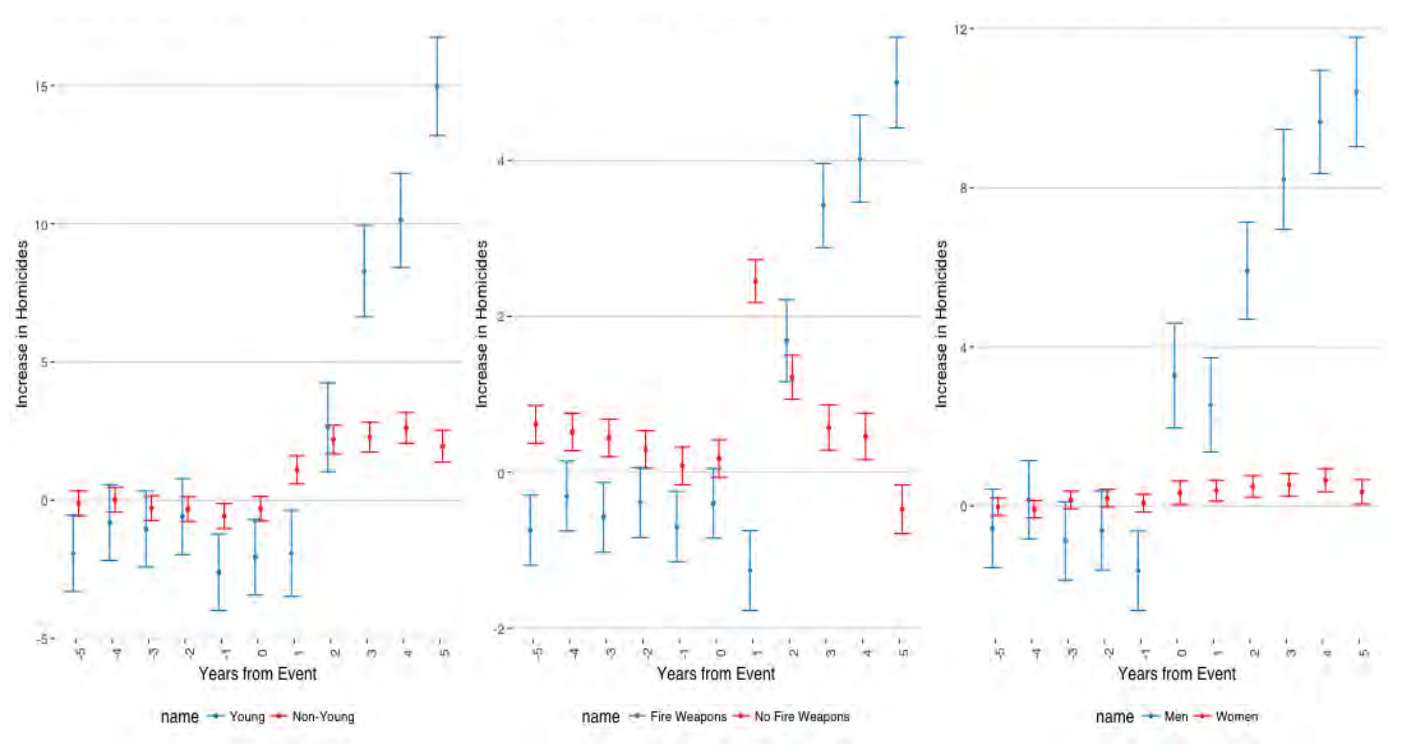

Figure 4.1: The dynamic of the relation between drug entry and violence by groups 



Figure 4.2: The dynamic of the relation between drug entry and violence by groups - Log transformed model

Notes: We show the estimates for the coefficients in the regression of homicide rates on drug entry and fixed effect for municipalities and time, and state-specific linear trend. We interact the drug entry variable with a time dummy variable for the 6 five years before the event and 5 five years after. Confidence intervals has significance level of $95 \%$. We add a constant $\left(50^{t}\right.$ hpercentile) to homicide rates to apply the log transformation.

\section{2}

\section{Effects of Drug Entry by Slum Presence}

In this section we discuss how the presence and the magnitude of slums ${ }^{1}$ interact with the association found between drug entry and violence.

We use the 2000 Brazilian census, where we can identify individuals that live in slums and create two variables: 1 . The percentage of people living in slums in a given municipality, and 2. a dummy variable that tells us if at least 1 person lives on slums for that municipality. We then interact those two measures, in separate regressions, with our measure of drug entry. To illustrate this data, for this year, approximately 6.5 million people were living in these sorts of places. Furthermore, we identify 225 municipalities, where slums were present.

We discussed before that the mere presence of drug markets are not necessarily associated with violence. We showed that, for our data, this

${ }^{1}$ IBGE defines slums as Aglomerados Subnormais: "They consists of at least 51 housing units (shacks, houses, ...), most of them lacking essential public services, occupying, or having occupied until recently, land owned by others (public or private) and being arranged, in general, in a disorderly manner and densities". They includes favelas, but also other sorts of very low-income territories. 
association is present after controlling for relevant factors that might be interacting with violence and drug entry. Furthermore, (59) tell us that, for the metropolitan region of Belo Horizonte, violence in favelas is contingent on the presence of drug markets.

Table 4.3 shows in columns (1)-(4) estimates for the interaction between the percentage of people living in slums and drug entry. Columns (3) and (4) restrict the results for municipalities with the presence of slums. In columns (5) and (6), we focus on the heterogeneity of the association between drug entry and violence that follows from the presence of slums. On even-numbered columns, we add state trends.

The estimates indicate that slums make the effect of drug entry on violence stronger. This is not true for the magnitude of the effect, since in column (4) the estimate of the interaction is statistically insignificant. However, column(6) shows a positive estimate, which indicates that any amount of people living in slums makes drug entry more associated with violence.

Table 4.3: Is the presence of slums making the association between drug entry and violence stronger?

\begin{tabular}{|c|c|c|c|c|c|c|}
\hline & \multicolumn{6}{|c|}{ Dependent Variable: Homicide Rate } \\
\hline & $(1)$ & $(2)$ & $(3)$ & $(4)$ & $(5)$ & $(6)$ \\
\hline Drug Entry & $\begin{array}{c}3.793^{* * *} \\
(0.231)\end{array}$ & $\begin{array}{c}2.870^{* * *} \\
(0.195)\end{array}$ & $\begin{array}{l}4.152^{*} \\
(2.190)\end{array}$ & $\begin{array}{c}4.034^{* * *} \\
(1.438)\end{array}$ & $\begin{array}{c}4.381^{* * *} \\
(0.244)\end{array}$ & $\begin{array}{c}2.829^{* * *} \\
(0.206)\end{array}$ \\
\hline Drug Entry x Slums(2000) & $\begin{array}{c}0.261^{* * *} \\
(0.039)\end{array}$ & $\begin{array}{c}0.259^{* * *} \\
(0.033)\end{array}$ & $\begin{array}{c}0.482^{* * *} \\
(0.168)\end{array}$ & $\begin{array}{c}0.081 \\
(0.111)\end{array}$ & & \\
\hline Drug Entry x Presence Slums(2000) & & & & & $\begin{array}{c}-1.119^{* *} \\
(0.539)\end{array}$ & $\begin{array}{r}2.366^{* * * *} \\
(0.452)\end{array}$ \\
\hline Year FE & Y & $\mathrm{Y}$ & $\mathrm{Y}$ & $\mathrm{Y}$ & $\mathrm{Y}$ & $\mathrm{Y}$ \\
\hline State Trend & $\mathrm{N}$ & $\mathrm{Y}$ & $\mathrm{N}$ & Y & $\mathrm{N}$ & $\mathrm{Y}$ \\
\hline Observations & 88,112 & 88,112 & 3,600 & 3,600 & 88,112 & 88,112 \\
\hline $\mathrm{R}^{2}$ & 0.622 & 0.740 & 0.504 & 0.796 & 0.621 & 0.740 \\
\hline
\end{tabular}

Note: This table shows the association between drug entry and violence considering heterogeneity in slums. The dependent variable is Homicide Rates by municipality as measured by Datasus SIM - Sistema de Informação sobre Mortalidade - comprising icd-10 codes X85x-X99x. Drug entry is measured as the dummy variable which 1 if hospitalizations due to drug use suddenly passes the cutoff of 10 drug cases. Columns differ on the variables being controlled. All regressions use population weights. ${ }^{* * *} \mathrm{p}<0.01{ }^{* *} \mathrm{p}<0.05 * \mathrm{p}<0.10$ 


\section{5}

\section{Conclusion}

This paper examines the association between the emergence of drug markets and violence, and we establish this in light of the question of whether additional contested resources generate violence in a setting where the state lacks presence to enforce its monopoly of violence. Two opposing forces may be determining which direction this association might take, the rapacity effect and the opportunity cost effect. The first tells us that temptation to prey on others and to defend generates more violence, while the second says that additional resources might generate increases on wages and, therefore, the opportunity cost of violence.

We use data on hospitalizations due to drug use provided by Brazil's publicly funded health care system (SUS) to capture the moment when drug markets emerge (drug entry) in a given municipality. After controlling for a set of fixed effect, we show that drug entry is positively associated with violence (homicide rates). On our preferred model, drug entry is associated with a $25 \%$ increase in homicides rates for the average municipality. We also show that this association is weaker in the first years after drug entry and becomes larger in the subsequent years. It stabilizes around the fourth year after drug entry in the long-run level of about a 4.2 increase in homicide rates.

We also show that the association between drug entry and violence is stronger for young males killed by fire weapons. This serves a double purpose: first it helps to evaluate whether our measure of drug entry is plausible and, second, it tells us that drug entry is mostly associated with portions of the population most related with drug markets, including battling for resources, exemplified by the rapacity effect. Lastly, we show that, for the municipalities with the presence of slums, this association is also stronger.

One aspect this work lacks is the fact that we don not use data on drug gangs/factions. During the 2000's, a number of drug factions were created throughout Brazil. For instance, São Paulo-based $P C C$ was born in that era. For example, the number of drug gangs established in a municipality may be fundamental, because most of the violence take place when drug markets go from monopoly to oligopoly and gangs start to aspire for each others resources. Furthermore, this type of data could tell us a more detailed story when, slums, 
drug markets and drug factions are present. We may be more specific to point whether drug markets in general are associated with violence in slums, or if the presence of established drug factions is necessary. 


\section{Bibliography}

[7] DUBE, O.; VARGAS, J. F.. Commodity price shocks and civil conflict: Evidence from colombia. The Review of Economic Studies, 80(4):1384-1421, 2013.

[9] FRYER, R. G.; HEATON, P. S.; LEVITT, S. D. ; MURPHY, K. M.. Measuring crack cocaine and its impact. Economic Inquiry, 51(3):1651-1681, 2013.

[10] GROGGER, J.; WILLIS, M.. The emergence of crack cocaine and the rise in urban crime rates. Review of Economics and Statistics, 82(4):519-529, 2000.

[11] ABDALLA, R. R.; MADRUGA, C. S.; RIBEIRO, M.; PINSKY, I.; CAETANO, R. ; LARANJEIRA, R.. Prevalence of cocaine use in brazil: data from the ii brazilian national alcohol and drugs survey (bnads). Addictive behaviors, 39(1):297-301, 2014.

[13] CERQUEIRA, D.. Mortes violentas não esclarecidas e impunidade no rio de janeiro. Economia aplicada, 16(2):201-235, 2012.

[20] LESSING, B.. As facções cariocas em perspectiva comparativa. Novos Estudos-CEBRAP, (80):43-62, 2008.

[21] CHIMELI, A.; SOARES, R. R.. The use of violence in illegal markets: Evidence from mahogany trade in the brazilian amazon. 2011.

[24] ON DRUGS, U. N. O.; CRIME. World drug report 2016. United Nations Publications, 2016.

[31] BECKER, G. S.. Crime and punishment: An economic approach. In: THE ECONOMIC DIMENSIONS OF CRIME, p. 13-68. Springer, 1968.

[32] REUTER, P.. Systemic violence in drug markets. Crime, Law and Social Change, 52(3):275-284, 2009.

[34] BIDERMAN, C.; DE MELlO, J. M. ; SCHNEIDER, A.. Dry laws and homicides: evidence from the são paulo metropolitan area. The economic journal, 120(543):157-182, 2010. 
[35] CERQUEIRA, D.; DE MELLO, J. M. ; OTHERS. Evaluating a national anti-firearm law and estimating the causal effect of guns on crime. PUC, Rio de janeiro. Departamento de Economia. Texto para Discussão, (607), 2013.

[36] DE MELLO, J. M.; SCHNEIDER, A.. Assessing são paulo's large drop in homicides: The role of demography and policy interventions. In: THE ECONOMICS OF CRIME: LESSONS FOR AND FROM LATIN AMERICA, p. 207-235. University of Chicago Press, 2010.

[37] BIDERMAN, C.; SERGIO DE LIMA, R.; PINHO DE MELlO, J. M. ; SCHNEIDER, A.. Pax monopolista and crime: the case of the emergence of the primeiro comando da capital in são paulo. 2014.

[38] CASTILlO, J. C.; MEJÍA, D. ; RESTREPO, P.. Scarcity without leviathan: The violent effects of cocaine supply shortages in the mexican drug war. 2014.

[39] HAUSMAN, J. A.; HALL, B. H. ; GRILICHES, Z.. Econometric models for count data with an application to the patents-r\&d relationship, 1984.

[40] GROSSMAN, H. I.. A general equilibrium model of insurrections. The American Economic Review, p. 912-921, 1991.

[41] GROSSMAN, H. I.; OTHERS. The creation of effective property rights. American Economic Review, 91(2):347-352, 2001.

[42] HIRSHLEIFER, J.. The technology of conflict as an economic activity. The American Economic Review, 81(2):130-134, 1991.

[43] HIRSHLEIFER, J.. The dark side of the force: Economic foundations of conflict theory. Cambridge University Press, 2001.

[44] HIRSHLEIFER, J.. The dark side of the force: Western economic association international 1993 presidential address. Economic Inquiry, 32(1):1-10, 1994.

[45] GAMBETTA, D.. The Sicilian Mafia: the business of private protection. Harvard University Press, 1996.

[46] SKAPERDAS, S.. Warlord competition. Journal of Peace Research, 39(4):435-446, 2002. 
[47] COLLIER, P.; HOEFFLER, A.. Greed and grievance in civil war. Oxford economic papers, 56(4):563-595, 2004.

[48] GROSSMAN, H. I.. Kleptocracy and revolutions. Oxford Economic Papers, 51(2):267-283, 1999.

[49] DAL BÓ, E.; DAL BÓ, P.. Workers, warriors, and criminals: social conflict in general equilibrium. Journal of the European Economic Association, 9(4):646-677, 2011.

[50] BuOnanno, P.; Durante, R.; Prarolo, G. ; VANIN, P.. Poor institutions, rich mines: resource curse in the origins of the sicilian mafia. The Economic Journal, 125(586), 2015.

[52] LEI, Y.-H.; MICHAELS, G.. Do giant oilfield discoveries fuel internal armed conflicts? Journal of Development Economics, 110:139-157, 2014.

[53] BERMAN, N.; COUTTENIER, M.; ROHNER, D. ; THOENIG, M.. This mine is mine! how minerals fuel conflicts in africa. 2015.

[54] AUTOR, D. H.. Outsourcing at will: The contribution of unjust dismissal doctrine to the growth of employment outsourcing. Journal of labor economics, 21(1):1-42, 2003.

[55] DOWDNEY, L.. Crianças do tráfico: um estudo de caso de crianças em violência armada organizada no Rio de Janeiro. 7letras, 2003.

[56] CARVALHO, L. S.; SOARES, R. R.. Living on the edge: Youth entry, career and exit in drug-selling gangs. Journal of Economic Behavior \& Organization, 121:77-98, 2016.

[57] GLAESER, E. L.; SACERDOTE, B.. Why is there more crime in cities? Journal of political economy, 107(S6):S225-S258, 1999.

[59] BEATO FILHO, C. C.; ASSUNÇÃO, R. M.; DA SILVA, B. F. A.; MARINHO, F. C.; REIS, I. A. ; DE MATTOS ALMEIDA, M. C.. Conglomerados de homicídios e o tráfico de drogas em belo horizonte, minas gerais, brasil, de 1995 a 1999 homicide clusters and drug traffic in belo horizonte, minas gerais state, brazil. Cad. Saúde Pública, 17(5):1163-1171, 2001.

[60] DE MELLO, J. M.; OTHERS. Assessing the crack hypothesis using data from a crime wave: the case of são paulo. Texto para Discussão, (586), 2010. 
[61] CARLINI, E.; NOTO, A. R.; GALDURÓZ, J. C. F. ; NAPPO, S. A.. Visao historica sobre o uso de drogas: passado e presente: Rio de janeiro e sao paulo. J Bras Psiquiatr, p. 227-236, 1996.

[62] CUNNINGHAM, S.; SHAH, M.. Decriminalizing indoor prostitution: Implications for sexual violence and public health. Technical report, National Bureau of Economic Research, 2014.

[63] ADDA, J.; MCCONNELL, B. ; RASUL, I.. Crime and the decriminalization of cannabis: Evidence from a localized policing experiment. Unpublished manuscript, University College London, 2010.

[64] OWENS, E. G.. Are underground markets really more violent? evidence from early 20th century america. American Law and Economics Review, 13(1):1-44, 2011.

[65] OWENS, E. G.. The birth of the organized crime? the american temperance movement and market-based violence. 2011.

[66] DIRK, R.; DE MOURA, L.. As motivações nos casos de letalidade violenta da região metropolitana do rio de janeiro. 2017. 


\section{Appendix}

Table A.1: Is drug entry associated with violence? (Cutoffs: 1, 2, 4)

\begin{tabular}{|c|c|c|c|c|c|c|}
\hline \multirow[b]{2}{*}{ Drug Entry } & \multicolumn{6}{|c|}{ Dependent Variable: Homicide Rate } \\
\hline & $\begin{array}{c}4.387^{* * *} \\
(0.231)\end{array}$ & $\begin{array}{c}-2.592^{* * *} \\
(0.197)\end{array}$ & $\begin{array}{c}4.855^{* * *} \\
(0.218)\end{array}$ & $\begin{array}{c}-1.250^{* * *} \\
(0.186)\end{array}$ & $\begin{array}{c}5.215^{* * *} \\
(0.214)\end{array}$ & $\begin{array}{c}0.956^{* * *} \\
(0.182)\end{array}$ \\
\hline Cutoff & 1 & 1 & 2 & 2 & 4 & 4 \\
\hline Year FE & $\mathrm{Y}$ & Y & $\mathrm{Y}$ & Y & $\mathrm{Y}$ & Y \\
\hline State Trend & $\mathrm{N}$ & Y & $\mathrm{N}$ & Y & $\mathrm{N}$ & Y \\
\hline Observations & 88,112 & 88,112 & 88,112 & 88,112 & 88,112 & 88,112 \\
\hline $\mathrm{R}^{2}$ & 0.622 & 0.739 & 0.622 & 0.739 & 0.623 & 0.739 \\
\hline
\end{tabular}

Note: This table shows the association between drug entry and violence. The dependent variable is Homicide Rates by municipality as measured by Datasus SIM - Sistema de Informação sobre Mortalidade - comprising icd-10 codes X85x-X99x. Drug entry is measured as the dummy variable which 1 if hospitalizations due to drug use suddenly passes the cutoff of $k$ drug cases. Columns in the value of the cutoff. All regressions use population weights. $* * * \mathrm{p}<0.01 * * \mathrm{p}<0.05 * \mathrm{p}<0.10$

Table A.2: Is drug entry associated with violence? (Cutoffs: 8, 12, 16)

\begin{tabular}{lcccccc}
\hline \hline \multicolumn{7}{c}{ Dependent Variable: Homicide Rate } \\
\hline Drug Entry & $\begin{array}{c}5.221^{* * *} \\
(0.219)\end{array}$ & $\begin{array}{c}3.292^{* * *} \\
(0.185)\end{array}$ & $\begin{array}{c}3.797^{* * *} \\
(0.227)\end{array}$ & $\begin{array}{c}3.546^{* * *} \\
(0.191)\end{array}$ & $\begin{array}{c}4.049^{* * *} \\
(0.228)\end{array}$ & $\begin{array}{c}3.490^{* * *} \\
(0.193)\end{array}$ \\
\hline Cutoff & 8 & 8 & 12 & 12 & 16 & 16 \\
Year FE & $\mathrm{Y}$ & $\mathrm{Y}$ & $\mathrm{Y}$ & $\mathrm{Y}$ & $\mathrm{Y}$ & $\mathrm{Y}$ \\
State Trend & $\mathrm{N}$ & $\mathrm{Y}$ & $\mathrm{N}$ & $\mathrm{Y}$ & $\mathrm{N}$ & $\mathrm{Y}$ \\
Observations & 88,112 & 88,112 & 88,112 & 88,112 & 88,112 & 88,112 \\
$\mathrm{R}^{2}$ & 0.622 & 0.740 & 0.621 & 0.740 & 0.621 & 0.740 \\
\hline \hline
\end{tabular}

Note: This table shows the association between drug entry and violence. The dependent variable is Homicide Rates by municipality as measured by Datasus SIM - Sistema de Informação sobre Mortalidade - comprising icd-10 codes X85x-X99x. Drug entry is measured as the dummy variable which 1 if hospitalizations due to drug use suddenly passes the cutoff of $k$ drug cases. Columns in the value of the cutoff. All regressions use population weights. ${ }^{* * *} \mathrm{p}<0.01 * * \mathrm{p}<0.05^{*} \mathrm{p}<0.10$ 
Table A.3: Is drug entry associated with violence? (Cutoffs: 1, 2, 4) - Log Transformed OLS

\begin{tabular}{lcccccc}
\hline \hline \multicolumn{7}{c}{ Dependent Variable: Homicide Rate } \\
\hline Drug Entry & $0.216^{* * *}$ & -0.010 & $0.215^{* * *}$ & $0.024^{* * *}$ & $0.196^{* * *}$ & $0.065^{* * *}$ \\
& $(0.008)$ & $(0.007)$ & $(0.007)$ & $(0.007)$ & $(0.007)$ & $(0.007)$ \\
\hline Cutoff & 1 & 1 & 2 & 2 & 4 & 4 \\
Year FE & $\mathrm{Y}$ & $\mathrm{Y}$ & $\mathrm{Y}$ & $\mathrm{Y}$ & $\mathrm{Y}$ & $\mathrm{Y}$ \\
State Trend & $\mathrm{N}$ & $\mathrm{Y}$ & $\mathrm{N}$ & $\mathrm{Y}$ & $\mathrm{N}$ & $\mathrm{Y}$ \\
Observations & 88,112 & 88,112 & 88,112 & 88,112 & 88,112 & 88,112 \\
$\mathrm{R}^{2}$ & 0.650 & 0.733 & 0.650 & 0.733 & 0.649 & 0.733 \\
\hline \hline
\end{tabular}

Note: This table shows the association between drug entry and violence. The dependent variable is Homicide Rates by municipality as measured by Datasus SIM - Sistema de Informação sobre Mortalidade - comprising icd-10 codes X85x-X99x. Drug entry is measured as the dummy variable which 1 if hospitalizations due to drug use suddenly passes the cutoff of $k$ drug cases. Columns in the value of the cutoff. All regressions use population weights. ${ }^{* * *} \mathrm{p}<0.01 * * \mathrm{p}<0.05 * \mathrm{p}<0.10$

Table A.4: Is drug entry associated with violence? (Cutoffs: 8, 12, 16) - Log Transformed OLS

Dependent Variable: Homicide Rate

\begin{tabular}{lcccccc}
\hline Drug Entry & $\begin{array}{c}0.150^{* * *} \\
(0.008)\end{array}$ & $\begin{array}{c}0.093^{* * *} \\
(0.007)\end{array}$ & $\begin{array}{c}0.099^{* * *} \\
(0.008)\end{array}$ & $\begin{array}{c}0.096^{* * *} \\
(0.007)\end{array}$ & $\begin{array}{c}0.088^{* * *} \\
(0.008)\end{array}$ & $\begin{array}{c}0.077^{* * *} \\
(0.007)\end{array}$ \\
\hline Cutoff & 8 & 8 & 12 & 12 & 16 & 16 \\
Year FE & $\mathrm{Y}$ & $\mathrm{Y}$ & $\mathrm{Y}$ & $\mathrm{Y}$ & $\mathrm{Y}$ & $\mathrm{Y}$ \\
State Trend & $\mathrm{N}$ & $\mathrm{Y}$ & $\mathrm{N}$ & $\mathrm{Y}$ & $\mathrm{N}$ & $\mathrm{Y}$ \\
Observations & 88,112 & 88,112 & 88,112 & 88,112 & 88,112 & 88,112 \\
$\mathrm{R}^{2}$ & 0.648 & 0.734 & 0.647 & 0.734 & 0.647 & 0.734 \\
\hline \hline
\end{tabular}

Note: This table shows the association between drug entry and violence. The dependent variable is Homicide Rates by municipality as measured by Datasus SIM - Sistema de Informação sobre Mortalidade - comprising icd-10 codes X85x-X99x. Drug entry is measured as the dummy variable which 1 if hospitalizations due to drug use suddenly passes the cutoff of $k$ drug cases. Columns in the value of the cutoff. All regressions use population weights. ${ }^{* * *} \mathrm{p}<0.01 * * \mathrm{p}<0.05^{*} \mathrm{p}<0.10$ 
Table A.5: Is drug entry associated with violence? (Cutoffs: 1, 2, 4) - Poisson Regression

\begin{tabular}{lcccccc}
\hline \hline \multicolumn{7}{c}{ Dependent Variable: Homicides } \\
\hline Drug Entry & $0.372^{* * *}$ & $0.114^{* * *}$ & $0.349^{* * *}$ & $0.089^{* *}$ & $0.309^{* * *}$ & $0.107^{* * *}$ \\
& $(0.086)$ & $(0.025)$ & $(0.085)$ & $(0.023)$ & $(0.085)$ & $(0.022)$ \\
& & & & & & 4 \\
Cutoff & 1 & 1 & 2 & 2 & $38 \%$ & $12 \%$ \\
Effect & $43 \%$ & $10 \%$ & $40 \%$ & $8 \%$ & $\mathrm{Y}$ & $\mathrm{Y}$ \\
Year FE & $\mathrm{Y}$ & $\mathrm{Y}$ & $\mathrm{Y}$ & $\mathrm{Y}$ & $\mathrm{N}$ & $\mathrm{Y}$ \\
State Trend & $\mathrm{N}$ & $\mathrm{Y}$ & $\mathrm{N}$ & $\mathrm{Y}$ & $\mathrm{N}$ & \\
Observations & 88,112 & 88,112 & 88,112 & 88,112 & 88,112 & 88,112 \\
$\mathrm{R}^{2}$ & 0.846 & 0.849 & 0.846 & 0.849 & 0.846 & 0.849 \\
\hline \hline
\end{tabular}

Note: This table shows the association between drug entry and violence. The dependent variable is Homicide Rates by municipality as measured by Datasus SIM - Sistema de Informação sobre Mortalidade - comprising icd-10 codes X85x-X99x. Drug entry is measured as the dummy variable which 1 if hospitalizations due to drug use suddenly passes the cutoff of $k$ drug cases. Columns in the value of the cutoff. All regressions use population weights. ${ }^{* * *} \mathrm{p}<0.01 * * \mathrm{p}<0.05 * \mathrm{p}<0.10$

Table A.6: Is drug entry associated with violence? (Cutoffs: 1, 2, 4) - Poisson Regression

\begin{tabular}{lcccccc}
\hline \hline \multicolumn{7}{c}{ Dependent Variable: Homicides } \\
\hline Drug Entry & $0.257^{* * *}$ & $0.128^{* * *}$ & $0.174^{* * *}$ & $0.107^{* * *}$ & $0.164^{* * *}$ & $0.065^{* * *}$ \\
& $(0.087)$ & $(0.024)$ & $(0.087)$ & $(0.027)$ & $(0.088)$ & $(0.028)$ \\
\hline Cutoff & 8 & 8 & 12 & 12 & 16 & 16 \\
Effect & $33 \%$ & $17 \%$ & $23 \%$ & $15 \%$ & $22 \%$ & $10 \%$ \\
Year FE & $\mathrm{Y}$ & $\mathrm{Y}$ & $\mathrm{Y}$ & $\mathrm{Y}$ & $\mathrm{Y}$ & $\mathrm{Y}$ \\
State Trend & $\mathrm{N}$ & $\mathrm{Y}$ & $\mathrm{N}$ & $\mathrm{Y}$ & $\mathrm{N}$ & $\mathrm{Y}$ \\
Observations & 88,112 & 88,112 & 88,112 & 88,112 & 88,112 & 88,112 \\
$\mathrm{R}^{2}$ & 0.846 & 0.849 & 0.846 & 0.849 & 0.846 & 0.849 \\
\hline \hline Note: & & & & ${ }^{*} \mathrm{p}<0.1 ;{ }^{* *} \mathrm{p}<0.05 ;{ }^{* * *} \mathrm{p}<0.01$
\end{tabular}

Note: This table shows the association between drug entry and violence. The dependent variable is Homicide Rates by municipality as measured by Datasus SIM - Sistema de Informação sobre Mortalidade - comprising icd-10 codes X85x-X99x. Drug entry is measured as the dummy variable which 1 if hospitalizations due to drug use suddenly passes the cutoff of $k$ drug cases. Columns in the value of the cutoff. All regressions use population weights. ${ }^{* * *} \mathrm{p}<0.01 * * \mathrm{p}<0.05 * \mathrm{p}<0.10$ 